\title{
Detecção de anticorpos anti-Toxoplasma gondii em animais de uma comunidade rural do Mato Grosso do Sul, Brasil
}

\section{Anti-Toxoplasma gondii antibody detection in animals from farms of a rural community of south of Mato Grosso do Sul, Brasil}

\author{
Joil Moreira Marques ${ }^{1}$; Fabiane Beatriz Isbrecht²; Thays Mizuki Lucas; \\ Isabela Maria Polido Guerra ${ }^{3}$; Aline Dalmolin'; \\ Rodrigo Costa da Silva ${ }^{5}$; Helio Langoni ${ }^{5}$; Aristeu Vieira da Silva ${ }^{6 *}$
}

Resumo

O presente trabalho avaliou a freqüência de anticorpos anti-Toxoplasma gondii em eqüídeos, gatos, cães, aves, suínos, bovinos e ovinos de propriedades rurais localizada no município de Eldorado, no sul do Estado do Mato Grosso do Sul. As amostras de sangue foram coletadas e o soro obtido examinado pelo método de aglutinação direta (MAD), sendo consideradas positivas amostras reagentes a títulos $\geq$ 25. A freqüência de animais reagentes ao teste de detecção de anticorpos foi: 22,89\% (46/201) em aves, 5,15\% (20/388) em bovinos, 47,61\% (20/42) em cães, 60,87\% (14/23) em eqüídeos, 57,14\% (8/14) em gatos, $14,7 \%$ (5/34) em suínos e em ovinos (0/14) não houve nenhum positivo. A maioria das espécies apresentou freqüências elevadas de anticorpos, o que traz preocupação, pois aponta possibilidade de risco para os humanos uma vez que estas espécies ou compartilham as mesmas fontes de infecção com o homem ou servem de alimento para ele.

Palavras-chave: Toxoplasmose, sorologia, epidemiologia, rural

\begin{abstract}
The rate of anti-Toxoplasma gondii antibodies was evaluated in equines, cats, dogs, poultry, pigs, cattle and sheep of farms in Eldorado, southern Mato Grosso do Sul. Blood samples were collected and sera were examined by the modified agglutination test (MAT), considering positives samples reactants with titers $\geq 25$. Rates of reactor animals in the antibody detection test were: $22.89 \%(46 / 201)$ in poultry, $5.15 \%(20 / 388)$ in cattle, $47.61 \%(20 / 42)$ in dogs, $60.87 \%(14 / 23)$ in equines, $57.14 \%(8 / 14)$ in cats, $14.7 \%(5 / 34)$ in pigs. None of the sheep $(0 / 14)$ were positive. High antibody rates were found in several species, a fact that raise concerns due to the possibility of risk to humans, once these animal species either share the same source of infection with humans or are food sources for them.
\end{abstract}

Key words: Toxoplasma gondii, antibodies, epidemiology, rural

1 Biólogo, Curso de Mestrado em Ciência Animal, Universidade Paranaense, UNIPAR, Campus Umuarama.

2 Curso de Graduação em Medicina Veterinária, UNIPAR, bolsista do Programa Institucional de Bolsas de Iniciação Científica, PIBIC / UNIPAR.

3 Curso de Graduação em Medicina Veterinária, UNIPAR, bolsista do Programa Externo de Bolsas de Iniciação Científica, PEBIC / UNIPAR-Fundação Araucária.

4 Curso de Graduação em Medicina Veterinária, UNIPAR, participante do Programa de Iniciação Científica, PIC / UNIPAR.

5 Núcleo de Pesquisa em Zoonoses, Faculdade de Medicina Veterinária e Zootecnia, Universidade Estadual Paulista - UNESP, Botucatu, SP.

6 Professor Doutor, Mestrado em Ciência Animal, UNIPAR. E-mail: aristeu@unipar.br

* Autor para correspondência 


\section{Introdução}

A toxoplasmose é uma doença causada por um parasita coccídio intracelular obrigatório, de distribuição mundial, denominado Toxoplasma gondii, constituindo-se numa das mais importantes zoonoses. O gato doméstico (Felis catus) e outros membros da família Felidae são os únicos hospedeiros definitivos conhecidos, enquanto que diversas espécies de mamíferos e aves são os hospedeiros intermediários. $\mathrm{Na}$ fase aguda da infecção o parasita encontra-se no estágio de taquizoítos, pondendo atingir todos os tecidos, inclusive a interface materno-fetal, e na fase crônica encontra-se no estágio de bradizoítos, que encistam em vários tecidos, principalmente no sistema nervoso central e musculatura (DUBEY; BEATTIE, 1988).

O homem e os animais podem se infectar principalmente por três formas: 1) ingestão de cistos em tecidos de hospedeiro intermediários; 2) ingestão de oocistos esporulados eliminados nas fezes de felinos; e 3) transmissão transplacentária de taquizoítos. A toxoplasmose freqüentemente é assintomática, porém, pode manifestar-se sem sintomatologia característica, por problemas nervosos e reprodutivos, caracterizados eplos abortamentos (TENTER; HECKEROTH; WEISS, 2000).

Desta maneira, para evidenciar a infecção dos animais e do ser humano, recorre-se freqüentemente à detecção de anticorpos séricos contra o parasito, uma vez que os mesmos perduram por diversos anos, e eventualmente, durante toda a vida do hospedeiro (DUBEY; BEATTIE, 1988). Entre os diversos métodos disponíveis, o método de aglutinação direta traz como vantagens poder ser aplicado às diferentes espécies animais, com resultados semelhantes aos de outros métodos, prescindindo de reagentes espécieespecíficos e equipamentos sofisticados (Da SILVA; CUTOLO, LANGONI, 2002).

Entre as espécies relevantes na transmissão de $T$. gondii, o estudo da infecção em felídeos é importante devido ao seu papel como contaminador do ambiente com oocistos. Por outro lado, os cães são considerados como altamente predispostos à infecção pelo parasito devido ao seu hábito alimentar e ao estreito contato com o solo contaminado (LANGONI et al., 2006). Sabe-se que entre as espécies exploradas para carne, a suína é a que representa a maior fonte de infecção em muitos paises (DUBEY, 1994). As aves domésticas, em especial as galinhas (Gallus gallus) criadas de forma extensiva, são ótimas indicadoras de contaminação ambiental, dado seus hábitos alimentares (DUBEY et al., 2003).

No ambiente rural evidenciam-se diversas fontes de infecção para os animais, podendo haver grande diferença entre os estudos, devido às condições de criação das diferentes espécies. Assim, existe necessidade de avaliações locais para se inferir a prevalência na população, uma vez que pode haver flutuação dos resultados dependendo da época e local examinados. Este trabalho teve como objetivo avaliar a freqüência de anticorpos anti- $T$. gondii em amostras de soro de animais de companhia e de produção em uma comunidade rural do Mato Grosso do Sul.

\section{Material e métodos}

Local de coleta

O Projeto de Assentamento (PA) Floresta Branca, local de realização deste estudo, localizase no município de Eldorado, sul do estado de Mato Grosso do Sul, distante $470 \mathrm{~km}$ de Campo Grande, capital do Estado, com uma população de 11.934 habitantes (BRASIL, 2007). A economia do município é voltada para a agropecuária, sendo as pecuárias de corte e leite, as culturas de soja, milho, mandioca e melancia suas principais atividades. O PA Floresta Branca possui 185 propriedades, contabilizando um total de 4.655 bovinos, 435 suínos, 5.108 aves, 223 eqüinos e 43 ovinos, segundo censo realizado pelo Instituto de Desenvolvimento Agrário, Assistência Técnica e Extensão Rural do 
estado de Mato Grosso do Sul (MARQUES, 2008). $\mathrm{O}$ número de cães e gatos não foi verificado neste censo. No PA a principal atividade econômica é representada pela produção de leite em regime extensivo, caracterizado ainda pela baixa adoção de tecnologia na produção e processamento do leite.

\section{Amostragem}

Para este estudo foram sorteadas 20 propriedades, onde foram coletadas amostras de sangue de $100 \%$ dos cães, gatos, ovinos e eqüídeos, e de cerca de 10\% dos bovinos, suínos e aves de cada propriedade, de forma aleatória, sem distinção de sexo, raça ou idade. Para os bovinos foram examinadas amostras de 73 propriedades, disponibilizadas pela Agência de Defesa Sanitária (IAGRO) do Estado do Mato Grosso do Sul, que coletava amostras de sangue de animais de até um ano de idade para avaliação de anticorpos contra o vírus da febre aftosa.

\section{Coleta de amostras}

As amostras de sangue foram coletadas pela punção da veia jugular em bovinos, suínos, eqüídeos, ovinos e gatos, e da veia cefálica em aves e cães, sendo acondicionadas em tubos de ensaio com tampa de borracha, devidamente identificados por um número de protocolo. Após a coleta de todas as amostras, as mesmas foram transportadas em contêiner refrigerado até o laboratório do Centro de Saúde do município de Eldorado centrifugadas a 1650 g por 15 minutos para promover a separação do soro. Separadas em alíquotas de $1 \mathrm{ml}$ e armazenadas em microtubos plásticos devidamente identificados. A seguir foram incubadas a $56^{\circ} \mathrm{C}$ por 30 minutos, e então armazenadas a $-20^{\circ} \mathrm{C}$. As amostras foram acondicionadas e transportadas em contêiner refrigerado, até o Laboratório de Medicina Veterinária Preventiva e Saúde publica da Universidade Paranaense, Campus Umuarama Sede, onde foram mantidas a $-20^{\circ} \mathrm{C}$ até o processamento.

\section{Exame sorológico}

O exame das amostras de soro foi realizado pelo método de aglutinação direta para detecção de anticorpos anti-T. gondii usando antígeno fixado pela formalina (DESMONTS; REMINGTON, 1980). Inicialmente foi realizada triagem do soro na diluição $1: 25$, seguidas de diluição seriadas do soro na base dois para determinação do título de anticorpos nas amostras reagentes à triagem. O ponto de corte utilizado foi 1:25 e em todas as determinações foram testados soros controle positivos e negativos.

\section{Dados epidemiológicos}

Foram obtidas no momento das visitas para coleta de sangue informações sobre a idade, sexo e hábitos alimentares dos cães e felinos. Dos animais de produção foram coletadas informações sobre idade, manejo e alimentação.

\section{Análise de dados}

A partir da freqüência de anticorpos anti- $T$. gondii os dados coletados para cães e gatos foram associados ao resultado do exame sorológico, utilizando-se o teste do Qui-quadrado ou o Teste Exato de Fischer, caracterizando uma análise univariada. Os mesmos testes foram aplicados aos dados disponíveis para as outras espécies animais. Em todas as análises foi considerado um nível de significância de 5\% (TRIOLA, 2005).

\section{Resultados e discussão}

Das 20 propriedades sorteadas foram coletadas amostras de sangue de 42 cães, 14 felinos, 23 eqüídeos, 34 suínos, 201 aves e 14 ovinos, bem como de 388 bovinos de 73 propriedades. A Tabela 1 apresenta a distribuição de positivos segundo a espécie avaliada e a Tabela 2 mostra a distribuição dos títulos de anticorpos segundo a espécie avaliada. 
Tabela 1. Freqüência absoluta (n), freqüência relativa (\%) e intervalo de confiança 95\% (IC95\%) de animais reagentes ao método de aglutinação direta para a detecção de anticorpos anti-Toxoplasma gondii, total de animais examinados e total da população, segundo a espécie, em uma comunidade rural. Eldorado, MS. 2007.

\begin{tabular}{|c|c|c|c|c|c|}
\hline \multirow[b]{2}{*}{ Espécie } & \multicolumn{3}{|c|}{ Positivos } & \multirow[b]{2}{*}{ Total examinado } & \multirow[b]{2}{*}{ População* } \\
\hline & № & $\%$ & IC95\% & & \\
\hline Aves & 46 & 22,89 & $17,62-29,18$ & 201 & 5108 \\
\hline Bovinos & 20 & 5,15 & $3,37-7,83$ & 388 & 4584 \\
\hline Cães & 20 & 47,61 & $33,05-62,34$ & 42 & $370 * *$ \\
\hline Eqüúdeos & 14 & 60,87 & $40,59-77,89$ & 23 & 223 \\
\hline Felinos & 8 & 57,14 & $32,29-78,73$ & 14 & $121 * *$ \\
\hline Ovinos & 0 & 0,0 & $0,17-21,81$ & 14 & 43 \\
\hline Suínos & 5 & 14,79 & $6,56-30,26$ & 34 & 435 \\
\hline
\end{tabular}

* População verificada em censo realizado pelo Instituto de Desenvolvimento Agrário e Extensão Rural do Mato Grosso do Sul (MARQUES, 2006).

** População estimada com base na média de animais nas propriedades examinadas.

Tabela 2. Freqüência absoluta dos títulos de anticorpos anti-T. gondii pelo método de aglutinação direta, em soros de cães, felinos, eqüídeos, suínos, aves e bovinos de uma comunidade rural de Eldorado, MS. 2007.

\begin{tabular}{cccccccccc}
\hline \multicolumn{1}{c}{ Títulos de anticorpos ao método de aglutinação direta } & \multicolumn{1}{c}{} \\
\hline Espécie & $\mathbf{2 5}$ & $\mathbf{5 0}$ & $\mathbf{1 0 0}$ & $\mathbf{2 0 0}$ & $\mathbf{4 0 0}$ & $\mathbf{8 0 0}$ & $\mathbf{1 6 0 0}$ & $\mathbf{3 2 0 0}$ & Total \\
\hline Cães & 3 & 4 & 2 & 3 & 2 & 4 & 1 & 1 & 20 \\
\hline Felinos & 0 & 0 & 2 & 0 & 1 & 3 & 1 & 1 & 8 \\
\hline Eqüídeos & 4 & 3 & 0 & 3 & 2 & 0 & 1 & 1 & 14 \\
\hline Suínos & 0 & 1 & 0 & 0 & 1 & 3 & 0 & 0 & 5 \\
\hline Aves & 4 & 2 & 4 & 4 & 9 & 11 & 7 & 5 & 46 \\
\hline Bovinos & 8 & 5 & 6 & 1 & 0 & 0 & 0 & 0 & 20 \\
\hline
\end{tabular}

Dos cães 40 cães examinados 20 (48\%; IC95\%: 33-62) foram positivos com títulos variando de 25 a 3200. Os resultados aproximam-se dos obtidos por Cabral et al. (1998) onde foram coletadas amostras de sangue de 327 cães de propriedades rurais do município de Uberlândia, $\mathrm{MG}$ e, pela imunofluorescência indireta, encontraram 180 (55\%; IC95\%: 50-60) amostras positivas. Garcia et al. (1999a) em 189 amostras de sangue de cães no município de Jaguapitã, PR, obtiveram uma freqüência de 84\% (IC95\%: 78-89) de positivos, diferindo deste trabalho.

Dos 14 felinos examinados, oito (57; IC95\%: 3279) foram positivos, com títulos entre 100 e 3200. Estes resultados aproximam-se dos de Garcia et al. (1999a), que examinaram 173 gatos no município de Jaguapitã sendo que 73\% (IC95\%: 66-79) destes animais foram positivos.

A Tabela 3 apresenta os dados epidemiológicos coletados para cães e gatos, com a avaliação de associação à positividade ao MAD. Apenas a idade nos cães esteve estatisticamente associada à presença anticorpos, tendo sido encontrados animais positivos apenas entre aqueles com mais de um ano. Nos felinos, apesar da associação não ser significativa, houve comportamento semelhante ao encontrado para os cães. Resultado semelhante foi encontrado no trabalho de Brito et al. (2002), que encontrou uma maior freqüência de cães positivos para a presença de IgG anti-Toxoplasma naqueles com mais de três anos de idade. 
As prevalências obtidas para cães e felinos neste trabalho, pode ser devida aos hábitos alimentares destes animais, em grande parte alimentados com restos de comida humana, além de serem criados soltos nas propriedades rurais, o que favorece o carnivorismo. Garcia et al. (1999a) apontam ainda que as vias de transmissão seriam diferentes para as duas espécies, principalmente a predação para felinos e o consumo de restos alimentares para os cães. Há de se salientar que eventualmente os animais podem ter acesso a restos de abortamentos, uma vez que em sete propriedades foi relatada esta ocorrência entre os animais.

Das 23 amostras de eqüídeos avaliadas 14 (61\%; IC 95\%: 40-78) foram positivas. Comparado ao trabalho de Da Silva et al. (2007), utilizando o MAD em eqüídeos, de 1984 amostras, 138 foram positivas (7\%; IC95\%: 6-8), prevalência mais baixa do que a obtida neste trabalho. Garcia et al. (1999b) em trabalho realizados em Jaguapitã, norte do Estado do Paraná, em 173 eqüídeos, obtiveram uma prevalência de 12\% (IC95\%: 8-18), sendo que $57 \%$ destes com titulo até 64 . Gazêta et al. (1997) em amostras coletadas de 430 animais no estado do Rio de Janeiro encontraram uma prevalência de 4\% (IC95\%: 3-7), também diferindo dos resultados deste trabalho. A diferença na freqüência de anticorpos em eqüídeos neste trabalho, em relação aos citados, pode se dever à idade dos animais. No caso dos cavalos e muares avaliados, todos são animais presentes na comunidade desde a sua formação, há cerca de dez anos. A prevalência da infecção em eqüídeos é mais comum em áreas úmidas e quentes, mas outros fatores podem estar associados, tais como a presença de gatos, idade dos animais e tipo de manejo (CHHABRA; GUPTA; GAUTAM, 1985).

Foram realizadas coletas de amostras de sangue de suínos em dez lotes, num total de 34 amostras. Destas, cinco (15\%) foram positivas para a presença de anticorpos anti-T. gondii pelo MAD. Quando comparados aos resultados obtidos por outro autores, verifica-se que outros fatores, não avaliados nesta espécie, tais como idade e alimentação podem influenciar na freqüência de animais positivos. Assim Garcia et al. (1999b), Tsutsui et al. (2003) e Moura et al. (2007) encontraram 24\%, 15\% e 8\% de animais positivos, respectivamente. Segundo Weigel et al. (1995) a presença de felinos e roedores esta relacionada a infecção toxoplásmica em suínos, e Assad-Rad, New e Patton (1995) encontraram associação da infecção em suínos com o manejo extensivo. Nas propriedades estudadas, a principal fonte de alimentação destes animais era constituída por milho e restos da alimentação humana. Além disso em todas as propriedades avaliadas, os animais eram criados em instalações rústicas, inclusive com o livre trânsito de outros animais, entre eles os gatos e roedores, cuja presença foi relatada em todas as propriedades. 
Tabela 3. Avaliação de dados epidemiológicos e a freqüência de anticorpos anti-Toxoplasma gondii em cães e felinos de uma comunidade rural de Eldorado, MS. 2007.

\begin{tabular}{|c|c|c|c|c|}
\hline \multirow[b]{2}{*}{ Variável estudada } & \multicolumn{2}{|c|}{ Cães } & \multicolumn{2}{|c|}{ Felinos } \\
\hline & Positivos / Total (\%) & Valor de $P$ & Positivos / Total (\%) & Valor de $\mathbf{P}$ \\
\hline \multicolumn{5}{|l|}{ Idade } \\
\hline$<1$ ano & $0 / 5(0)$ & \multirow{2}{*}{0,0309} & $0 / 3(0)$ & \multirow{2}{*}{0,0699} \\
\hline$\geq 1$ ano & $19 / 35(54)$ & & $7 / 10(70)$ & \\
\hline \multicolumn{5}{|l|}{ Sexo } \\
\hline Fêmea & $3 / 7(43)$ & \multirow{2}{*}{0,5592} & $3 / 4(75)$ & \multirow{2}{*}{0,3426} \\
\hline Macho & $16 / 33(48)$ & & $4 / 9(44)$ & \\
\hline \multicolumn{5}{|l|}{ Alimentação } \\
\hline & estos de comida humana & & & \\
\hline Não & $0 / 2(0)$ & \multirow{2}{*}{0,2692} & $0 / 1(0)$ & \multirow{2}{*}{0,4615} \\
\hline Sim & $19 / 38(50)$ & & $7 / 12(58)$ & \\
\hline \multicolumn{5}{|l|}{ - Leite } \\
\hline Não & $8 / 13(62)$ & \multirow{2}{*}{0,1854} & $2 / 5(40)$ & \multirow{2}{*}{0,4126} \\
\hline Sim & $11 / 27(41)$ & & $5 / 8(62)$ & \\
\hline \multicolumn{5}{|l|}{ - Carne crua } \\
\hline Não & $8 / 17(47)$ & \multirow{2}{*}{0,6073} & $6 / 10(60)$ & \multirow{2}{*}{0,4370} \\
\hline Sim & $11 / 23(48)$ & & $1 / 3(33)$ & \\
\hline \multicolumn{5}{|l|}{ - Quirera/fubá } \\
\hline Não & $18 / 33(54)$ & \multirow{2}{*}{0,0615} & $6 / 11(54)$ & \multirow{2}{*}{0,7307} \\
\hline Sim & $1 / 7(14)$ & & $1 / 2(50)$ & \\
\hline \multicolumn{5}{|l|}{ - Ração } \\
\hline Não & $16 / 30(53)$ & \multirow{3}{*}{0,1809} & $6 / 12(50)$ & \multirow{3}{*}{0,5384} \\
\hline Sim & $3 / 10(30)$ & & $1 / 1(100)$ & \\
\hline \multicolumn{3}{|l|}{ - Caça } & & \\
\hline Não & $17 / 36(47)$ & \multirow[b]{2}{*}{0,6580} & $0 / 3(0)$ & \multirow[b]{2}{*}{0,0699} \\
\hline Sim & $2 / 4(50)$ & & $7 / 10(70)$ & \\
\hline
\end{tabular}

Estatística: valores de P menores que 0,05 indicam associações significativas, pelos testes do $\chi^{2}$ ou Exato de Fischer.

A freqüência de soros de galinhas positivos foi de 46 (23\%; IC95\%: 18-29) de um total de 201 aves, entre galinhas $(\mathrm{n}=195)$ e galinhas d'Angola $(\mathrm{n}=6)$. A freqüência de lotes com pelo menos uma ave positiva foi 11 (58\%; IC95\%: 36-77) de um total de 19 lotes que possuíam aves, com variação de $8,33 \%$ a $100 \%$ de aves positivas por lote. Garcia et al. (2000) em 155 amostras coletadas na área rural de Jaguapitã no Estado do Paraná obteve $10 \%$ de positividade. Dubey et al. (2002) coletaram amostras de 82 galinhas, do estado de São Paulo, encontrando 32 (39\%) amostras soro positivas para o MAD. Dubey et al. (2003), na região de Santa Isabel do Ivaí, PR, obtiveram nove $(22 \%)$ dos 40 soros examinados positivos pelo MAD. Quando avaliadas com relação à idade, verificou-se neste trabalho, que em 50 aves com idade aproximada de três anos, a freqüência de positivos foi $48 \%$, enquanto que em aves com idade menor, foram $14 \%$ de positivos. Esta diferença demonstrou ser significativa ( $p<0,0001)$. O encontro de aves positivas para a presença de anticorpos anti-T.gondii demonstra a contaminação ambiental e o risco de infecção a que a população humana e animal desta comunidade rural estão submetidas. 
Entre os bovinos, foram coletadas 388 amostras, sendo $186(48 \%)$ de animais até um ano de idade, e $202(52 \%)$ de bovinos com mais de um ano. A freqüência de animais positivos foi de $2 \%$ (IC95\%: 1-5) e 7,92\% (IC95\%: 5-13) para animais com menos e com mais de um ano de idade, respectivamente; houve diferença estatisticamente significativa $(p=0,0111)$. Quando considerados as 79 propriedades examinadas, 14 (18\%) tiveram pelo menos um animal positivo. Trabalho realizado com amostras de soro de bovinos de corte, no município de Campo Grande, apontou taxa de infecção de 4\%, semelhante à encontrada neste estudo (ARAÚJO; CARVALHO; BALBUENA, 1998). Por outro lado, Marana et al. (1994), pesquisando anticorpos anti- $T$. gondii em amostras de soro de animais coletadas em propriedades leiteiras da região norte do Paraná, encontraram $48 \%$ de positivos. Garcia et al. (1999b), também no norte do Paraná, examinaram 400 bovinos e obtiveram prevalência de $26 \%$. Estes resultados demonstram que o tipo de exploração, e conseqüentemente, o nível de exposição dos animais às fontes de infecção, influenciam a taxa de soropositivos. Desta maneira, apesar dos animais da comunidade estudada serem utilizados para a exploração leiteira, o manejo extensivo a que são submetidos pode ser um dos fatores que levaram à uma menor freqüência de anticorpos anti-T. gondii.

Todos os ovinos examinados, oriundos de uma propriedade, foram negativos.

\section{Conclusões}

Os resultados obtidos permitem delinear uma cadeia de eventos que demonstra que a infecção por Toxoplasma gondii está disseminada na comunidade rural estudada. $\mathrm{O}$ encontro de felinos positivos demonstra que em algum momento estes animais contaminaram o solo com oocistos, e as taxas de infecção dos animais de produção, notadamente as aves e eqüídeos, suportam a hipótese de contaminação ambiental. Por outro lado, o manejo dos animais, tanto os de produção quanto os de estimação, que são criados na sua maioria soltos, muitas vezes alimentados com restos de comida humana, favorece o contato dos mesmos com as fontes de infecção. Finalmente, a associação entre idade e taxas de infecção, verificadas principalmente em cães, aves e bovinos, demonstra que os animais são expostos de uma forma contínua.

Este trabalho foi submetido para apreciação e aprovado pelo Comitê de Ética em Pesquisa Envolvendo Experimentação Animal (CEPEEA) da Universidade Paranaense em reunião realizada no dia 28/09/2006.

\section{Agradecimentos}

À Universidade Paranaense, UNIPAR, pelo apoio financeiro para realização deste projeto. À Agência de Defesa Sanitária do Estado do Mato Grosso do Sul, IAGRO, pela disponibilização de parte das amostras de soro de bovinos. À Fundação Araucária pelo apoio financeiro na forma de Bolsa de Iniciação Científica. Aos acadêmicos do curso de Medicina Veterinária da UNIPAR, Rafael Menegatti, Kelly Cristina Martini, Thiago de Oliveira Zamprogna, Francislaine Aparecida dos Reis Lívero, Ronaldo César da Rosa, pelo auxílio nas coletas de amostras. À Secretaria Municipal da Saúde do Município de Eldorado, por ceder o laboratório para preparo das amostras.

\section{Referências}

ARAÚJO, F.R., CARVALHO, C.M.E., BALBUENA, C.B. Levantamento sorológico para Toxoplasma gondii em bovinos de corte do Estado de Mato Grosso do Sul, Brasil. Revista Brasileira de Medicina Veterinária, Rio de Janeiro, v.20, n.5, p.201-203, 1998.

ASSAD-RAD, A. M.; NEW, J. C.; PATTON, S. Risk factors association with transmission of Toxoplasma gondii to sows kept in different management systems in Tennessee. Veterinary Parasitology, Amsterdam, v. 57, n. 4, p. 289-297, 1995.

BRASIL. Instituto Brasileiro de Geografia e Estatística. Cidades@. 2007. Disponível em: <http://www.ibge.gov. br/home/>. Acesso em: 20 out. 2007. 
BRITO, A. F.; SOUZA, L. C.; Da SILVA, A. V.; LANGONI, H. Epidemiological and serological aspects in canine toxoplasmosis in animals with nervous symptoms. Memórias do Instituto Oswaldo Cruz, Rio de Janeiro, v. 97, n. 1, p. 31-35, 2002.

CABRAL, D. D.; SILVA, D. A. O.; MIRANDA, E. O.; CUNHA, L.; FUKUSSIMA, A. C.; STUTZ, W.; BASTOS, J. E. D.; FERREIRA, F. A. Detecção de anticorpos anti-Leishmania (Viannia) braziliensis e $L$. donovani, anti-Trypanosoma cruzi e anti-Toxoplasma gondii em cães da área rural do município de Uberlândia, MG, Brasil. Veterinária Notícias, Uberlândia, v. 4, n. 1, p. 15-19, 1998.

CHHABRA, M. B.; GUPTA, S. L.; GAUTAM, O. P. Toxoplasma seroprevalence in animals in northern India. International Journal of Zoonoses, Taipei, v. 12, n. 2, p. 136-142, 1985.

Da SILVA, A. V.; CUTOLO, A. A.; LANGONI, H. Comparação da reação de imunofluorescência indireta e do método de aglutinação direta na detecção de anticorpos anti-Toxoplasma em soros de ovinos, caprinos, caninos e felinos. Arquivos do Instituto Biológico, São Paulo, v. 69, n. 1, p. 7-11, 2002.

Da SILVA, A. V.; LANGONI, H.; PEZERICO, S. B.; LIMA, V. Y. Utilization of modified agglutination test and indirect immunofluorescent antibody test for the detection of Toxoplasma gondii antibodies in naturally exposed horses. Brazilian Journal of Veterinary Research and Animal Science, São Paulo, v. 44, n. 1, p. 27-32, 2007.

DESMONTS, G.; REMINGTON, J. S. Direct agglutination test for diagnosis of Toxoplasma infection : method for increasing sensitivity and specificity. Journal of Clinical Microbiology, Washington, v. 11, n. 6, p. 562568, 1980.

DUBEY, J. P. Toxoplasmosis. Journal of the American Veterinary Medical Association, Schaumburg, v. 205, n. 2, p. 1593-1598, 1994.

DUBEY, J. P.; BEATTIE, C. P. Toxoplasmosis of animals and man. Bocan Raton: CRC Press, 1988.

DUBEY, J. P.; GRAHAM, D. H.; BLACKSTON, C. R.; LEHMANN, T.; GENNARI, S. M.; RAGOZO, A. M. A.; NISHI, S. M.; SHEN, S. K.; KWOK, O. C. H.; HILL, D. E.; THULLIEZ, P. Biological and genetic characterisation of toxoplasma gondii isolates from chickens (Gallus domesticus) from São Paulo, Brazil: unexpected findings. International Journal for Parasitology, Parkville, v. 32, n. 1, p. 99-105, 2002.
DUBEY, J. P.; NAVARRO, I. T.; GRAHAM, D. H.; DAHL, E.; FREIRE, R. L.; PRUDENCIO, L. B.; SREEKUMAR, C.; VIANNA, M. C.; LEHMANN, T. Characterization of Toxoplasma gondii isolates from free range chickens from Paraná, Brazil. Veterianry Parasitology, Amsterdan, v. 17, n. 3, p. 229-234, 2003.

GARCIA, J. L.; NAVARRO, I. T.; OGAWA, L.; MARANA, E. R. N. Soroprevalência do Toxoplasma gondii em galinhas (Gallus gallus domesticus) de criações domésticas, oriundas de propriedades rurais do norte do Paraná, Brasil. Ciência Rural, Santa Maria, v. 30, n. 1, p. 123-127, 2000.

GARCIA, J. L.; NAVARRO, I. T.; OGAWA, L.; OLIVEIRA, R. C. Soroepidemiologia da toxoplasmose em gatos e cães de propriedades rurais do município de Jaguapitã, estado do Paraná, Brasil. Ciência Rural, Santa Maria, v. 29, n. 1, p. 99-104, 1999a.

GARCIA, J. L.; NAVARRO, I. T.; OGAWA, L.; OLIVEIRA, R. C. Soroprevalência do Toxoplasma gondii em suínos, bovinos, ovinos e eqüinos, e sua correlação com humanos, felinos e caninos, oriundos de propriedades rurais do norte do Paraná - Brasil. Ciência Rural, Santa Maria, v. 29, n. 1, p. 91-97, 1999b.

GAZÊTA, J. S.; DUTRA, A. I. A.; NORBERG, A. N.; SERRA-FREIRE, N. M.; SOUZA, W. J. S.; AMORIM, M.; LOPES, L. M. S. Freqüência de anticorpos antiToxoplasma gondii em soros de eqüinos no Estado do Rio de Janeiro, Brasil. Revista Brasileira de Parasitologia Veterinária, Rio de Janeiro, v. 6, n. 1, p. 87-91, 1997.

LANGONI, H.; PEZERICO, S. B.; SILVA, R. C.; CASTRO, A. P. B. C.; Da SILVA, A. V.; PADOVANI, C. R.. Serological profile of anti-Toxoplasma gondii antibodies in apparently healthy dogs of the city of Botucatu, SP, Brazil. Journal of Venomous Animals and Toxins Including Tropical Diseases, Botucatu, v. 12, n. 1, p. 142-148, 2006.

MARANA, E. R. M.; NAVARRO, I. T.; VIDOTTO, O.; FREIRE, R. L.; LOTT, R. Ocorrência de anticorpos anti-Toxoplasma gondii em bovinos de corte, abatidos em matadouros do norte do Paraná - Brasil. Semina, Londrina, v. 15, n. 1, p. 38-40, 1994.

MARQUES, J. M., Da Silva, D. V., Correia, N. A. B., Velásquez, G., Da Silva, R. C., Langoni, H. Da Silva, A. V. Prevalence and risk factors for human toxoplasmosis in a rural community. Journal of Venomous Animals and Toxins Including Tropical Diseases, Botucatu, v. 14, n. 4, p. 673-684, 2008. 
MOURA, A. B.; OSAKI, S. C.; ZULPO, D. L.; MARANA, E. R. M. Ocorrência de anticorpos contra Toxoplasma gondii em suínos e ovinos abatidos no município de Guarapuava, PR, Brasil. Revista Brasileira de Parasitologia Veterinária, Rio de Janeiro, v. 16, n. 1, p. 54-56, 2007.

TENTER, A. M.; HECKEROTH, A. R.; WEISS, L. M. Toxoplasma gondii: from animals to humans. International Journal of Parasitology, Parkville, v. 30, n. 12/13, p. 1217-1258, 2000.

TRIOLA, M. F. Introdução à estatística. Rio de Janeiro: LTC, 2005. $476 \mathrm{p}$.
TSUTSUI, V. S.; NAVARRO, I. T.; FREIRE, R. L.; FREITAS, J. C.; PRUDENCIO, L. B.; DELBEM, A. C. B.; MARANA, E. R. M. Soroepidemiologia e fatores associados à transmissão do Toxoplasma gondii em suínos do norte do Paraná. Archives od Veterinary Science, Curitiba, v. 8, n. 2, p. 27-34, 2003.

WEIGEL, R. M.; DUBEY, J. P.; DYER, D.; SIEGEL, A. M. Risk factors for transmission of Toxoplasma gondii on swine farms in Illinois. American Journal of Tropical Medicine and Hygiene, Deerfield, v. 81, n. 5, p. 736-741, 1995. 
